\title{
DESIGNING NATIONAL POLICY AND STRATEGIES FOR INCLUSIVE DEVELOPMENT: ACCELERATING INFRASTRUCTURE DEVELOPMENT FOR GROWTH AND PROSPERITY
}

\author{
Mohammed Ali Berawi ${ }^{1 *}$ \\ ${ }^{1}$ Faculty of Engineering, Universitas Indonesia, KampusUI Depok, Depok 16424, Indonesia
}

Many governments have increasingly emphasized a need to strengthen capacity to design national development policy and strategy in creating sustainable development. Responding to this necessity, Rembuk Nasional 2017, Indonesia's National meeting initiated by the interdisciplinary scientific and professional community was conducted to evaluate and further improve national strategies and performance in twelve development sectors. Rembuk Nasional 2017 was attended by Republic of Indonesia's president, ministers, governors, majors, members of parliaments, entrepreneurs, academicians, NGOs, and the public.

As the head of the Rembuk Nasional committee for the infrastructure and connectivity development sector, I agree that the momentum on accelerating infrastructure and connectivity development programs to achieve sustainable development objectives, stimulate economic growth, reduce poverty, and improve the quality of life of the people should be continuously supported.

\section{The 12 Recommendations}

Considering the massive programs involved in Indonesia's infrastructure development and the substantial amount of financial development allocation, there is a need to collaborate on strategies for government and private sectors and develop effective and efficient decision-making and policies related to infrastructure development. The committee proposed 12 points of recommendations based on the evaluation of current government programs using four indicators: planning and execution; institutions and policies; finance and partnership; and environment, law and social indicators.

The following recommendations are proposed to enhance Indonesia's infrastructure and connectivity development strategies and programs:

1. Establish a dedicated infrastructure development agency focused on formulating, establishing, coordinating, and evaluating policies as well as implementing multi-sector infrastructure development.

2. Establish a public-private partnership (PPP) unit in each province of Indonesia to accelerate the investment process and execute sustainable infrastructure development and regional connectivity.

3. Establish and manage the Land Bank for accelerating sustainable infrastructure development.

4. Apply value-added engineering in infrastructure planning and development to enhance project feasibility.

5. Increase the role of universities in collaboration with government and industry to enhance the planning and development of infrastructure and connectivity programs.

6. Channel technology and knowledge transfer into developing mega infrastructure projects through a R \& D center, improve human resource skills, utilize big data in infrastructure,

\footnotetext{
*Corresponding author's email: maberawi@eng.ui.ac.id, Tel. +62-21-7270029, Fax.+62-21-7270028 Permalink/DOI: https://doi.org/10.14716/ijtech.v8i5.860
} 
and facilitate the development of machinery, production equipment, and materials processing industries.

7. Support ongoing infrastructure and connectivity development using multi-year funding allocation as set forth in the medium and long-term master plan for development.

8. Support small and medium scale construction service businesses through a special loan scheme, as well as provide incentives and facilities for construction service business actors to expand their markets to other countries.

9. Facilitate the use of alternative non-state budget financial sources for infrastructure funding and enhancing capacity building for infrastructure financial institutions.

10. Balance the infrastructure and connectivity development programs aimed at (a) enhancing economic growth and productivity and (b) improving people's welfare and alleviating poverty.

11. Increase the participation of local and national entrepreneurs in infrastructure development and connectivity via state-owned and private enterprise collaboration.

12. Ensure legal aspects are properly implemented in infrastructure development processes and are transparent, ethical, and competitive.

Successful implementation of the above policies requires government action addressing all existing challenges and upgrading current policies and strategies.

\section{Enhancing Technology Performance}

Many research projects have been attempted to discover breakthroughs in developing and improving engineering technologies for a wide range of applications. Creating innovative products, optimizing performance, and altering processes to eliminate unwanted outcomes in this have been considered as ways to enhance added value. This edition, we are pleased to present twenty selected papers dedicated to various studies in technology design and engineering areas as a way to improve end-result performance.

The first paper, written by J. Fajrin, Y. Zhuge, F. Bullen, and H. Wang, presents the structural behavior of newly-developed hybrid structural insulated panels (SIPs). The authors argue that the proposed hybrid SIPs exhibited a much larger area under the load-deflection curve including toughness of the material and its ability to sustain larger compression strain prior to reaching their ultimate loads.

The next paper, written by X. Cui, Z. Tian, S. Cui, and Q. Jin, proposes a new blasting vibroseis technique utilizing the homogeneity, isotropy, and incompressibility of water to reduce damage to adjacent rock from blast waves. As a result, the authors argue that blasting vibroseis shows potential for a practical and cost-effective alternative to drilling and blasting for the exploration of geologic structures.

The third paper, written by M.A.O. Mydin, examines the effects of egg white on lime mortar's physical and mechanical properties. The author argues that the compressive and flexural strength of the lime mortar increased with the increasing percentage of egg white added into lime mortar until the mixture reached $6 \%$ egg white.

The fourth paper, written by C. Niken, E. Tjahjono, and F. Supartono, examines the cause of on a long-term deformation difference by shrinkage between the beams and columns of high performance concrete with compressive strength of $60 \mathrm{MPa}$. The authors argue that the long-term deformation behavior is determined by autogenous behavior, while autogenous behavior in columns is influenced by abnormal swelling. 
The fifth paper, written by S.Srikanth and A. Mehar, presents models for estimating the equivalency units of different vehicle types on multilane highways. The authors argue that the unique multiple non-linear approach can be used to accurately estimate the equivalency units of individual vehicle types under heterogeneous traffic conditions.

The next paper, written by N.M. Isa, S.N. Kamaruzzaman, O. Mohamed, and M.A. Berawi, presents an overview of the facility management (FM) functions in a value management workshop. The authors argue that the five elements of FM functions and their impact on a value management study is categorized as client satisfaction, energy efficiency, ergonomics, operation and maintenance, space management, and sustainability.

The seventh paper, written by T.H. Panjaitan, presents hybrid traditional dwellings and the authoritative power of the social and cultural system in customary house design. The author argues that the modern house is required to co-exist with multi-functional traditional spaces, therefore the architecture and its position of respect within society ensures the continuity of the social system and cultural values.

The eighth paper, written by S. Novianto, A.S. Pamitran, R. Koestoer, J.T. Oh, and K. Saito, presents the characteristics of propane (R-290) as a replacement for conventional refrigerants. The authors found that results show a laminar flow for liquid R-290 and a turbulence flow for vapor. The pressure drop decreases with increasing liquid Reynolds number and decreasing heat flux.

The next paper, written by M. Mohebbi and M. Hashemi, presents the design of a two degrees of freedom model of an unbalanced engine, reducing its vibrations by Active Force Control (AFC). The authors argue that when the AFC loop was engaged with the PID controller, vibrations were reduced to nearly zero in both frequency and amplitude.

The tenth paper, written by S. Giwa, C. Nwaokocha, C. Ogunbona, and O. Shittu, proposes the production of hydrogen from various aqueous sources using two sets of hydrolysis experiments. The authors argue that that urine followed by sea water and fufu effluent had the highest volume and flow rate of hydrogen, whereas the effectiveness value was highest for deionized water, followed by tap water and sea water.

The eleventh paper, written by J. Tapadar, R. Thakur, P. Chetia, S.K. Tamang, and S. Samanta, investigates the effects of process parameters of wire cut electrical discharge machining (WEDM) on Magnesium Silicon Carbide MMC with 5\% SiC in particulate form. The authors argue that pulse on-time and pulse off-time were the most significant parameters among others in predicting the material removal rate (MRR) and surface roughness (SR), respectively.

The next paper, written by W.A. Adi, A. Manaf, and Ridwan, investigates the magnetic properties and electromagnetic characterization of $\mathrm{La}_{0.8} \mathrm{Ba}_{0.2} \mathrm{Fe}_{\mathrm{x}} \mathrm{Mn}_{1 / 2(1-\mathrm{x})} \mathrm{Ti}_{1 / 2(1-\mathrm{x})} \mathrm{O}_{3}(\mathrm{x}=0.1-0.8)$. The authors argue that electromagnetic wave absorption reaches $95 \%$ at the highest peak frequency of 14.1 $\mathrm{GHz}$ in the sample of $\mathrm{x}=0.3$, with a relatively thin sample thickness of about $1.5 \mathrm{~mm}$.

The thirteenth paper, written by F. Febrianti, K. Syamsu, and M. Rahayuningsih, presents the bioethanol production from tofu waste by simultaneous saccharification and fermentation (SSF) using a microbial consortium. The author argues that the production of bioethanol by SSF using a microbial consortium for 72 hours was $7.69 \mathrm{~g} / \mathrm{L}$ of bioethanol, with a product yield $(\mathrm{Yp} / \mathrm{s})$ of $0.23 \mathrm{~g}$ ethanol/g substrate and substrate conversion efficiency of $88 \%$.

The fourteenth paper, written by S.D. Shetty and N. Shetty, investigates the inhibiting effect of N-benzyl-N'-phenyl thiourea (BPTU) and N-cyclohexyl-N'-phenyl thiourea (CPTU) on mild steel using the Tafel extrapolation technique. The authors argue that the inhibition was governed 
by a chemisorption mechanism and the presence of inhibitors substantially reduced the metal dissolution.

The next paper, written by A.E. Pramono, I. Rebet, and A. Zulfa, examines the electrical and mechanical properties of phenolic resin composites made from Gigantochloaapus carbon fiber, or bamboo carbon fiber reinforced polymer (BCFRP) composites. The authors found instabilities in the impact strength of bamboo carbon fiber and phenolic resin composites.

The sixteenth paper, written by A. Equbal, M.D.I. Equbal, A.K. Sood, and M.D.A. Equbal, presents electroplating using aluminum charcoal (Al-C) paste on FDM (Fused deposition modelling) parts through two different routes. The authors argue that despite shell cracking in a few electroplated samples, the Al-C route is also capable of producing good copper deposition on FDM samples.

The next paper, written by F. Rahmawati, I. Permadani, D.G. Syarif and S, Soepriyanto, investigates electrical properties of various compositions of yttria-stabilized zirconia, YSZ prepared from local zircon sand. The authors argue that the yttrium ions of $\mathrm{Y}^{3+}$ doping changed the cell parameter of $\mathrm{ZrO}_{2}$ crystal. It indicates that the $\mathrm{Y}^{3+}$ entered the $\mathrm{ZrO}_{2}$ structure and produced vacancy sites.

The eighteenth paper, written by P. Pangestu, D. Gunawan, and S. Hansun, presents the use of a histogram equalization to enhance images' contrast. The authors argue that the histogram equalization was successfully implemented using optical character recognition (OCR) preprocessing with an ability to show $74.95 \%$ of the information hidden in the image.

The nineteenth paper, written by B. Irmawati, H. Shindo, and Y. Matsumoto, presents a dependency annotation scheme for extracting syntactic features from a sentence. The authors argue that the extended annotation scheme improved the accuracy of a dependency parser, and the error correction task demonstrates that training data using syntactic features obtain better correction.

The last paper, written by M.N.S. Zainudin, M.D.N Sulaiman, N. Mustapha, T. Perumal, and R. Mohamed, presents hybrid feature selection based on an accelerometer sensorto recognize complex activities. The authors argue that the proposed method using relief-f and differential evolution produced better performance in minimizing and eliminating the least significant features before it is fed into the classifier model.

I hope that this special edition of IJTech conveys some new insights in the way we conduct our research. I am pleased to accept and respond to any comment or enquiry you may have on the direction and content of IJTech, and I invite you to join us in this venture by sending your work for consideration.

With warmest regards from Jakarta,

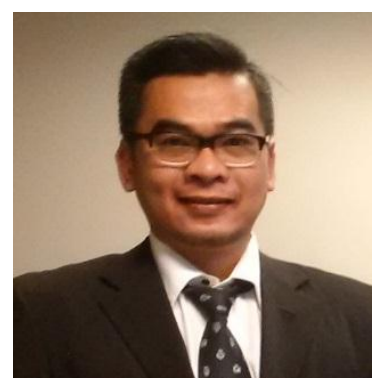

Dr. Mohammed Ali Berawi Editor in Chief 